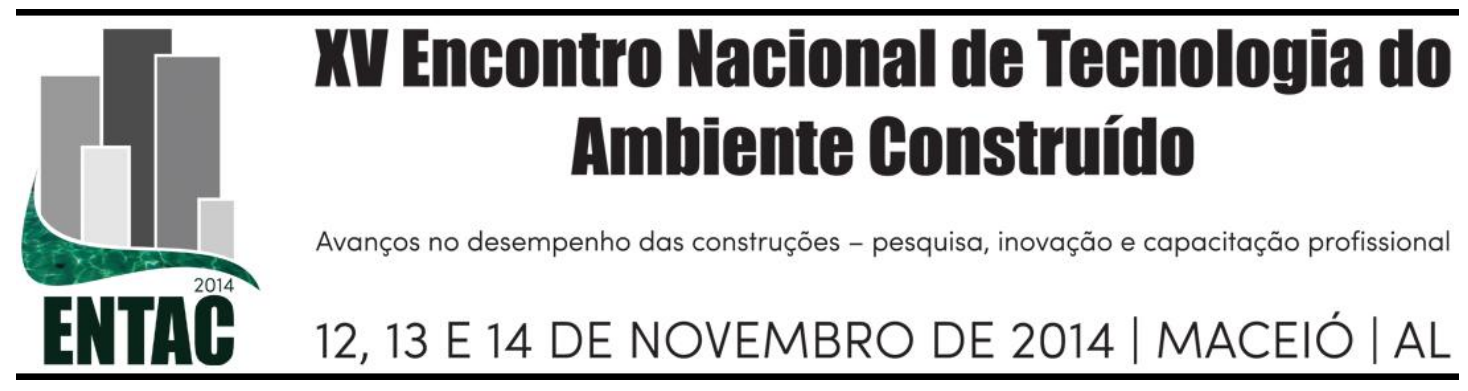

\title{
ANÁLISE DE SOLUÇÕES CONSTRUTIVAS PARA INTERFACES DE PAREDES DE TAIPA
}

\section{VERALDO, Ana Carolina (1); YUBA, Andrea Naguissa (2); MILANI, Ana Paula da Silva (3)}

(1) Universidade Federal de Mato Grosso do Sul, Campo Grande/MS, anacarolinaveraldo@ hotmail.com

(2) Universidade Federal de Mato Grosso do Sul, Campo Grande/MS: naguissa@ gmail.com

(3) Universidade Federal de Mato Grosso do Sul, Campo Grande/MS: $\underline{\text { ana.milani@ufms.br }}$

\begin{abstract}
RESUMO
O efetivo potencial da técnica construtiva de taipa, assim como outras técnicas de terra crua, como possibilidades construtivas na construção civil atual, tendo em vista a busca da sustentabilidade, requer a execução de muitas ações setoriais e também as de cunho técnico. Assunto que ainda está em curso é o do detalhamento de projeto e execução específico para essa técnica, principalmente se mecanizado, visando o desempenho da edificação como um todo, com vistas ao conforto visual, boas condições de salubridade e facilidade de execução. Este trabalho objetiva analisar o atendimento às expectativas de soluções construtivas para interfaces de paredes de taipa com outros subsistemas de uma edificação em taipa. Os dados apresentados são derivados da construção de um protótipo de uma edificação térrea. As interfaces analisadas são taipa-alicerce, taipa-taipa (em T e L), taipa-alvenaria, taipa-cobertura, taipa-revestimentos e taipa-esquadrias. São apresentadas as condicionantes que determinaram a definição de soluções, com base em revisão de literatura, o projeto dos detalhes e as expectativas, o as built, as modificações sugeridas e a avaliação do estado físico das interfaces em relação às expectativas. Os resultados mostram que algumas soluções de detalhamentos construtivos foram efetivas nos requisitos de conforto visual e facilidade de execução e não alteraram as qualidades das paredes de taipa. Outras, entretanto, resultantes de deformações da forma ou de intervenções pós desforma, ocasionaram interferências no comportamento da taipa e também desconforto visual.
\end{abstract}

Palavras-chave: taipa, habitação social, habitação rural, mecanização.

\begin{abstract}
The potential of rammed earth construction technique, as well as other earth construction techniques for a more sustainable building construction sector, requires sectoral actions and also technical ones. Architectural detailing and construction process standardization is still ongoing for this technique, especially if mechanized, aiming the best performance of the buildings, related to visual comfort, good health conditions and easiness to be built, because of specific issues of the material. This paper aims to analyze the relationship between architectural detailing (mainly interfaces), the performance expectations and post construction results. The presented data were obtained by a house prototype construction. The conditions, details, expectations, as built, evaluation and feedback are presented. The results show that some constructive solutions were effective in detailing requirements for visual comfort and construction easiness and did not affect the quality of the rammed earth walls. Some of them, however, resulted in addition of interference in walls behavior and aesthetic discomfort, mainly caused by formwork weaknesses or post-rammed interferences.
\end{abstract}

Keywords: rammed earth, housing, rural housing, mechanization. 


\section{INTRODUÇÃ̃O}

A alta disponibilidade de terra, associada aos avanços da tecnologia, fazem dessa matéria-prima uma potencial alternativa para atender aos desafios da construção sustentável. Em algumas partes da América do Norte, Austrália e Nova Zelândia, as construções de taipa, com solo estabilizado utilizam formas semelhantes às de concreto armado moldado in loco e compactadores pneumáticos, dentre outras inovações, o que melhorou a produtividade e o desempenho do produto para o consumidor, permitindo à inserção da técnica no mercado da construção com competitividade (SUZUKI, KRAYENHOFF, 2014; JAQUIN, 2008).

As construções de terra crua, mesmo quando incorporam materiais mais recentes como o cimento para sua estabilização, ainda possuem benefícios ambientais, podendo resultar em menores índices de energia incorporada e emissões de carbono do que edificações equivalentes, feitas com materiais convencionais, como concreto, aço ou alvenaria (JAGADISH, 1988; VENKATARAMA REDDY, JAGADISH, 2001).

Pesquisas sobre caracterização tipológica das patologias, estado e suas causas em edificações patrimoniais de terra (FONSECA, 2007) são fontes de solução para os detalhamentos atuais, entretanto os aspectos construtivos e formais da taipa atualmente necessitam de diretrizes de design estruturais mais racionais (JAQUIN, 2008). CLAIR, COURT (2011) observam uma modificação no tipo arquitetônico e nos modos de construir, partindo de um desenho mais tradicional (pequenas aberturas e paredes espessas) para um desenho adaptado à disponibilidade de outros materiais e técnicas, além das próprias exigências e necessidades funcionais dos tempos atuais (painéis independentes alternados com outros materiais, elementos e sistemas construtivos). Esta concepção contemporânea criou uma série de interfaces entre diferentes tipos de materiais, que nem sempre são executadas pela mesma equipe de construtores e que acabam gerando defeitos na superfície do painel e conexões pouco engenhosas.

\section{Figura 1 - Concepção tradicional (esquerda) e contemporânea (direita) da taipa}

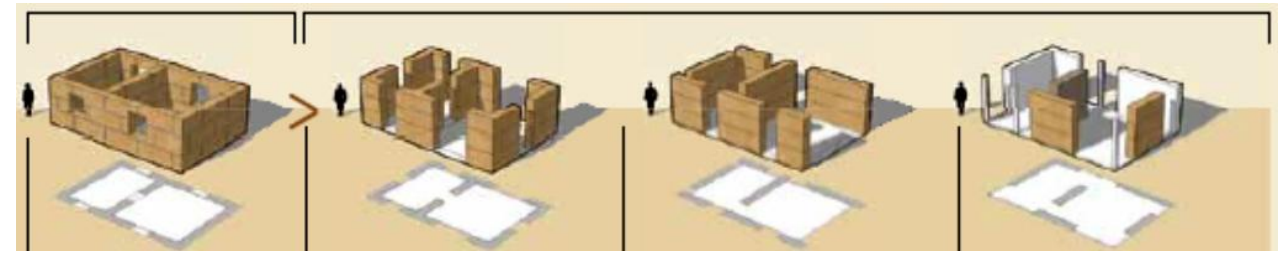

Fonte: CLAIR, E. COURT, J. (2011).

O desconhecimento das especificidades do material como suscetibilidade à abrasão superficial, poder de absorção de água, propensão à ocorrência de patologias e baixa tolerância a correções pós-execução (GONZÁLEZ, 2006; FONSECA, 2007; CEPED, 1984), só contribuem para agravar o quadro de patologias executivas.

As construções de terra demandam soluções de detalhamentos construtivos que evitem degradações, de modo que a edificação possa ter um bom desempenho ao longo do tempo. Na ausência de normas brasileiras, os códigos de outros países são os documentos disponíveis para nortear o desenvolvimento das construções no Brasil. Assim, a norma de desempenho tem um potencial de contornar essa questão, pois determina o desempenho a ser atingido pelo produto e não o modo como deve ser produzido.

Nesse contexto, este trabalho objetiva analisar o atendimento às expectativas de soluções construtivas para interfaces de paredes de taipa com outros subsistemas de uma edificação. 
O método adotado para o estudo consiste de: revisão bibliográfica para elaboração dos detalhamentos construtivos (item 2); definição de critérios e procedimentos de avaliação (item 3.2); construção do protótipo (item 3.1 e 4); avaliação do resultado e modificações propostas (item 4). As limitações da pesquisa são descritas no item 3.2.

\section{ASPECTOS CONSTRUTIVOS E FORMAIS}

O processo construtivo consiste basicamente em moldar in loco paredes de terra crua através da compactação da mistura de solo e aditivos, dentro de formas especiais, produzindo paredes maciças que dispensam a aplicação de revestimentos convencionais como rebocos e pinturas. Dentre variadas possibilidades de soluções formais e materiais, estão:

- Base da parede: devem proteger as paredes da umidade ascendente e ainda, da água de chuva que respinga nas paredes. Fonseca (2007) descreve edificações de taipa históricas em Avis, Portugal com fundações em pedra, elevadas do nível do terreno, numa altura média de $0,50 \mathrm{~m}$, mas códigos atuais de construção em terra (WALKER, STANDARDS AUSTRALIA, 2002; MANIATIDIS, WALKER, 2003) indicam o uso de fundações radier e sapata corrida para a base dos painéis;

- Quinas: as ações humanas e de outros seres vivos, como insetos e vegetação são fatores a considerar, por serem causadores de anomalias no material (biopatologias). São áreas de vulnerabilidade a danos por atrito de passagem e onde processos erosivos são mais evidentes. Nas edificações antigas os cunhais eram reforçados com pedra, endentadas no bloco de taipa (Fonseca, 2007). Soluções mais econômicas na atualidade são os chanfros;

- Aberturas: vãos nas paredes de taipa são pontos sensíveis da construção. Nos projetos de janelas e portas contemporâneos é perceptível que atualmente se evitam as vergas, deixando livre todo o pé direito (ver exemplo na Figura 1) ou embutindose molduras de madeira durante a compactação (EASTON, MCHENRY, NZS 4299:1998 e WALKER, STANDARDS AUSTRALIA apud MANIATIDIS, WALKER, 2003). Nas edificações antigas, os vãos tinham reduzidas dimensões porque era comum a fissuração na taipa, provocado por tensões que ocorriam entre as esquadrias e as paredes e também pela presença de vergas mal dimensionadas que provocavam esforços de flexão excessivos no material;

- Cobertura: Fonseca (2007) relata que foram identificados beirais nas edificações coloniais de taipa de Avis, com um balanço de apenas 0,20m, arrematados com tijolos nos topos das paredes. Topos inclinados são evitados, dada a dificuldade de realizar a compactação e até mesmo os cortes pós-compactação. Cintas são usadas a fim de melhorar a resistência à tração das paredes de taipa quando sujeitos a altas cargas laterais, que podem provocar fissuras nos painéis. Tais cintas são também uma interface entre a parede e a cobertura, fazendo o duplo papel de distribuição das cargas e ancoragem contra os efeitos de sucção. Na ausência de um berço de madeira ou concreto, a cobertura pode ser fixada diretamente na taipa (MANIATIDIS, WALKER, 2003);

- Tubulações: os códigos e normas internacionais geralmente recomendam não embutir tubulações de água nas paredes de terra. Para os eletrodutos, há recomendações diversas: aparente ou se embutido, que seja no terço central da espessura da parede sem exceder $10 \%$ de sua espessura e com furos menores do que $300 \mathrm{~mm}$ ou realizados com cortes pós compactação (EASTON, KEABLE, SAZS 724:2001 e WALKER, STANDARDS AUSTRALIA apud MANIATIDIS, WALKER, 2003); 
- Revestimentos e acabamentos: a ação do vento e da água retira partículas das camadas superficiais, com prejuízo para a espessura da taipa e sua compacidade. Em Avis, a arquitetura de taipa era revestida com rebocos feitos de cal e areia, o que provocava o aparecimento de patologias, dada a pouca capacidade de deformar, incompatível com o comportamento da terra. O uso de tintas plásticas, além de ser passível de questionamento pelo prejuízo para a imagem da edificação de terra, resulta em problemas pela ação da umidade entre o revestimento e acabamento ou entre a taipa e acabamento. Impermeabilizantes à base de PVA ou emulsões à base de silicone sobre a superfície da parede repelem a água, enquanto permitem a saída do vapor (WALKER, STANDARDS AUSTRALIA, 2002).

Os maiores problemas identificados nessa revisão são relacionados à água, em suas diversas formas, evidenciando um ponto que demanda grande atenção para aplicação em locais de clima predominantemente tropical. Assim, há limites à transferência das recomendações internacionais dadas as diferenças climáticas e até mesmo práticas construtivas em relação à realidade brasileira, o que expõe a lacuna de pesquisa tratada neste trabalho.

\section{MÉTODO DE AVALIAÇÃo}

\subsection{O caso estudado}

O estudo foi conduzido com base nos dados obtidos com a execução de um protótipo de habitação social de $105 \mathrm{~m}^{2}$, vinculado a ações de pesquisa e extensão na UFMS. O propósito do protótipo é evidenciar a viabilidade do uso da terra como material de construção e da técnica de taipa para gerar oportunidades de trabalho com foco principalmente nas áreas rurais.

Figura 2 - Planta (a), vistas do protótipo (b, c) e forma (d)

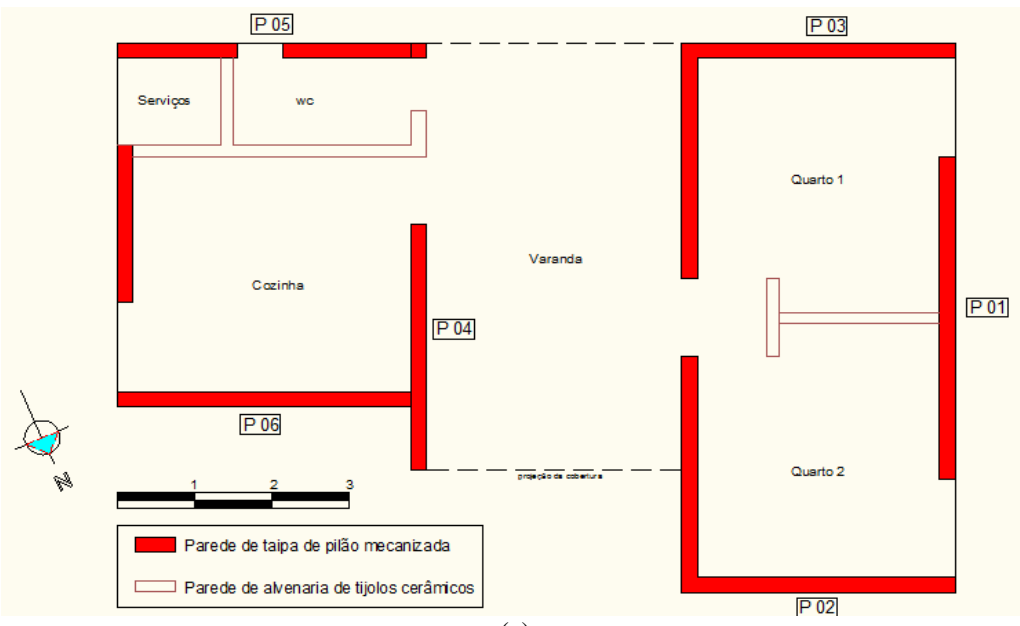

(a)

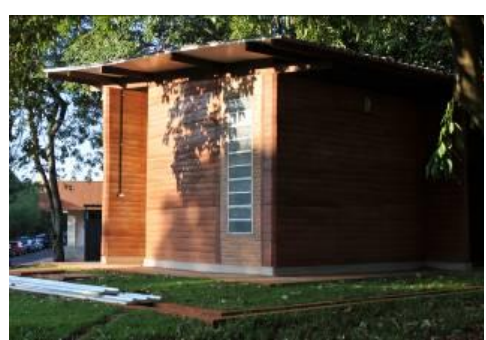

(b)

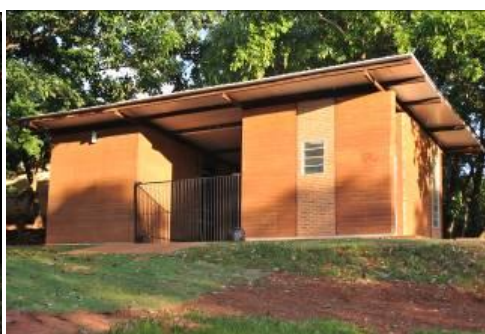

(c)

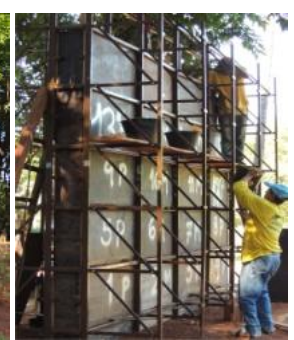

(d)

Fonte: CCS/UFMS e do autor 
Foi motivado pela análise de que a habitação social nesse meio atualmente segue modelos urbanos de forma e produção, o que resulta em problemas de adaptação e logística.

Com base nisso, o protótipo, como um todo, teve como principais modificações tecnológicas (em relação ao modo tradicional de construção) a introdução de mecanização da mistura, transporte e compactação; a substituição de armadura metálica por macrofibra de polipropileno no concreto da fundação, a introdução de microfibra de polipropileno na mistura da taipa, o uso de formas mistas (metal-compensado) e o uso de cobertura metálica sanduíche. A introdução das modificações é resultante de parcerias com fabricantes de máquinas e materiais e consultorias com prestadores de serviço de execução de paredes de taipa. Os problemas também motivaram a busca de soluções, as mais simplificadas possíveis (rol de materiais, equipamentos e grau de especialização da mão de obra), para os detalhamentos construtivos. A descrição dos materiais e técnicas utilizados nos subsistemas é apresentada no item 4.

\subsection{Procedimento de avaliação}

Para a coleta de dados, a construção do protótipo, principalmente na fase de execução das paredes, foi acompanhada por pelo menos um membro da equipe de pesquisa. As atividades foram filmadas, fotografadas e anotadas em fichas-padrão. Para a avaliação utilizou-se como base os requisitos de desempenho relacionados às exigências de habitabilidade apresentadas na NBR 15575:2013 (ABNT, 2013), também analisadas em CBIC (2013), e que permitem a avaliação por verificação in loco, visando a futura contribuição para a elaboração de métodos expeditos para avaliação de edificações de terra. Por essa razão, não foram avaliadas as exigências que necessitem de ensaios em laboratório ou equipamentos mais sofisticados.

Limitações da pesquisa: mesmo com a definição de critérios de avaliação (a seguir), a análise tem um grau de subjetividade pela falta de critérios de avaliação e normas desenvolvidos especificamente para o caso das edificações de terra e também por não ter sido definido um critério de ponderação entre as questões analisadas. Limita-se também aos dados obtidos em protótipo, tratando-se, portanto de uma primeira aproximação do assunto, havendo a necessidade futura de agregar mais objetividade à análise.

Os critérios adotados nesta pesquisa são: estanqueidade: as interfaces não devem permitir umidade ascendente do solo, percolação de umidade das paredes de fachada, janelas e cobertura e entre ambientes internos da edificação (CBIC, 2013); salubridade (saúde, higiene e qualidade do ar): as interfaces não devem apresentar frestas ou reentrâncias que facilitem a infestação de insetos, aves e roedores ou proliferação de micro-organismos, bactérias e passagem de gases tóxicos e poeira (CBIC, 2013); conforto tátil: os detalhamentos construtivos e as paredes de taipa não devem prejudicar as atividades rotineiras (caminhar, apoiar, limpar, brincar, posicionar móveis) e nem sofrerem degradações pelas condições de uso; conforto visual: as características superficiais (cor, textura e acabamento) das paredes de taipa devem ser mantidas; exequibilidade: o detalhamento deve buscar a máxima facilidade de execução, interferindo o mínimo possível na produtividade e considerar a melhor relação custobenefício.

Para cada detalhe avaliado, foram considerados: proposta (decisões para os detalhamentos construtivos); expectativas (resultados esperados em relação aos critérios de desempenho definidos acima); as built (descrição do que foi construído, razões para modificação, interferências na taipa, desempenho); retroalimentação (modificações 
sugeridas pós-execução, com base em revisão bibliográfica e nas avaliações intermediárias durante a obra).

Foram analisadas as seguintes interfaces: taipa-fundação; taipa-taipa (em Te L); taipaalvenaria; taipa-cobertura; taipa-instalações; taipa-esquadrias (somente portas) e taipaacabamentos.

\section{RESULTADOS OBTIDOS}

\section{Quadro 1 - Taipa-fundação}

Proposta: fundação radier com base para as paredes de concreto

Expectativa: que a base de concreto, impermeabilizada, cumprisse a função de rodapé. Para isto seria necessário que tanto o piso, a base e a forma da taipa estivessem perfeitamente alinhados, aprumados, nivelados, nas dimensões indicadas em projeto e sem irregularidades na superfície, de modo que as faces internas da forma encostassem perfeitamente na base.

As built: falhas executivas dificultaram o contato entre a forma e a base (falta de alinhamento da base, deformações da estrutura da forma, irregularidades no nivelamento do piso e erros de dimensionamento) o que acarretou o surgimento de vãos, que tiveram que ser preenchidos com papel. $\mathrm{Na}$ desforma, foram observadas falhas de compactação na base da parede (reentrâncias e desagregações), resultado da falta de adensamento. Além disso, a base ficou um pouco mais estreita do que a largura da forma e isto gerou uma diferença de alinhamento entre eles.

Modificação: com a obra em andamento optou-se por acoplar uma peça de aço em "T" entre a taipa e a base de concreto, a fim de vedarem-se os vãos e melhorar o nivelamento da interface, que foi revestida depois com um rodapé de argamassa.
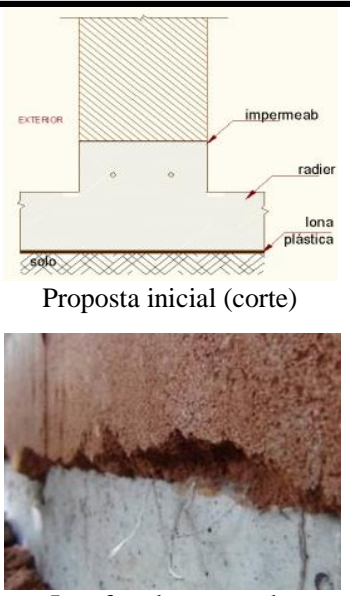

Interface base-parede

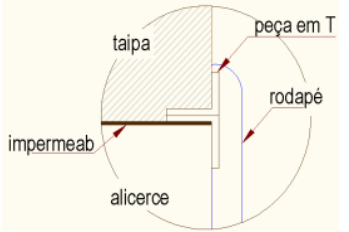

Remediação (corte)

Avaliação: a peça metálica em T criou uma proteção para a borda externa da parede de taipa. É uma peça de baixo custo comumente encontrada no mercado, que supre a necessidade de um rodapé de proteção para a base das paredes, sem necessitar de serviços especializados. Entretanto por não ter sido inserida em todas as paredes, optou-se por revesti-la com um rodapé de argamassa, uniformizando o acabamento ao redor de toda a edificação.

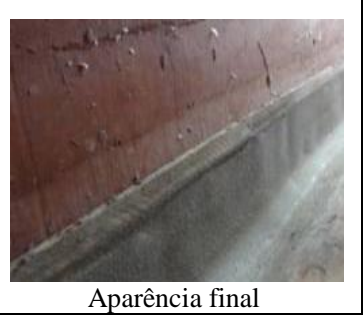

Fonte: do autor

\section{Quadro 2 - Taipa-taipa (T)}

\section{Proposta: criar junta de encaixe na intersecção em "T"}

Expectativa: que o painel pronto estivesse no prumo, de modo que a forma encostasse na face e a amarração não apresentasse defeitos. Houve discussão sobre a possibilidade de se fazer um acabamento chanfrado no encontro dos painéis.

As built: a falta de prumo do painel pronto dificultou o encontro da forma com a face da parede e, além disso, foi necessária a improvisação com chapas menores de compensado para o fechamento da forma nos cantos. $\mathrm{Na}$ moldagem do painel 4 foi inserida, dentro da forma, uma peça de madeira a fim de moldar o rebaixo para a amarração dos painéis. Esse ponto

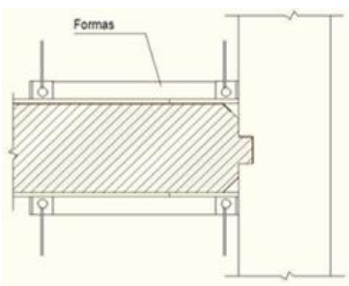

Proposta inicial (planta) demandou compactação manual. 
Avaliação: a junta demandou modificações na forma, que, improvisada, ficou mal apoiada, resultando em uma compactação mal sucedida e consequente reentrância com abertura maior que $3 \mathrm{~mm}$. Isso pode comprometer a salubridade, e a reentrância torna-a mais vulnerável aos agentes climáticos. Houve surgimento de trinca $(1 \mathrm{~mm})$ na face oposta do painel 4 e marcas antiestéticas que alteraram a homogeneidade e regularidade da superfície da taipa. Desta forma, a intersecção em T apresentou dificuldade executiva porque a forma não é adequada para esse tipo de detalhe.

Modificações sugeridas: reforma das formas, inserindo-se uma peça exclusiva para estas intersecções.

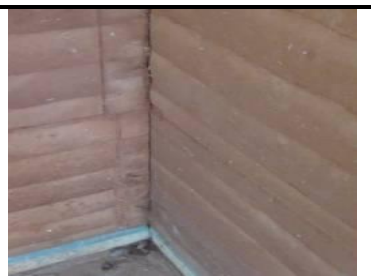
Aparência da interface em T

(a)

Fonte: CCS/UFMS e do autor; Minke, 2006 (a)

\section{Quadro 3 - Taipa-taipa em "L"}

Proposta: solucionar as quinas de $90^{\circ}$, substituindo-as por chanfros a $45^{\circ}$

Expectativa: evitar a degradação por atrito.

Avaliação: o detalhe deu um acabamento que possibilitou melhor proteção das quinas contra erosão e desagregação por atrito. Apresentou bom acabamento, pois evitou irregularidades recorrentes das quinas "vivas". No que se refere à exequibilidade apresentou facilidade de inserção da peça triangular nos cantos da forma, não atrapalhando a produtividade e auxiliando na vedação dos cantos, que normalmente são pontos de vazamento da mistura na compactação.

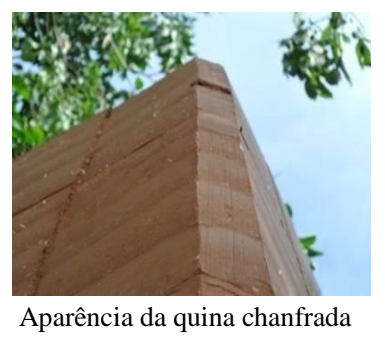

Fonte: do autor

\section{Quadro 4 - Taipa-alvenaria de tijolos maciços (fachada)}

Proposta: executar paredes de alvenaria, entre paredes de taipa, para o assentamento das janelas

Expectativa: evitar o uso de vergas e que a interface tivesse um bom aspecto (linearidade, enquadramento).

As built: as faces das paredes de taipa estavam fora do prumo, com áreas desagregadas, o que prejudicou a aparência dos tijolos externamente, dado que os vãos foram preenchidos com argamassa para compensar o defeito. $\mathrm{O}$ detalhe também evidenciou a diferença de largura da base de concreto em relação à parede de tijolo, mais estreita.

Modificação: com a obra em andamento optou-se por pintar as manchas do excedente de argamassa com uma tinta de terra e cortar a sobra da base de concreto.

Avaliação: a interface criou fissuras de dilatação entre os materiais. $O$ corte feito na base de concreto eliminou a parte exposta que poderia acumular poeira, desta forma a interface tende a não apresentar problema de salubridade. A quina chanfrada propiciou maior proteção a atritos pelas condições de uso do ambiente. O conforto visual foi prejudicado devido ao conjunto de pequenas falhas (falta de enquadramento, linearidade, fissuras de dilatação e manchas de argamassa). A amarração entre paredes foi executada conforme orientações de projeto e não houve dificuldade executiva.

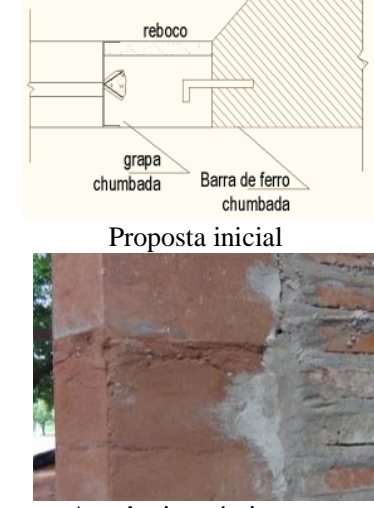

Aparência pré-pintura

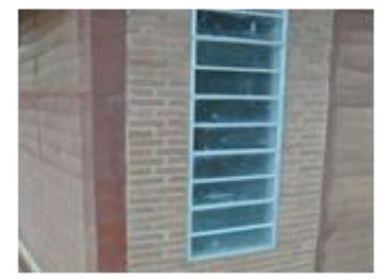

Aparência pós-pintura

Fonte: CCS/UFMS e do autor 


\section{Quadro 5 - Taipa-cobertura}

Proposta: moldar solocimento plástico no topo das paredes planas e inclinadas, formando uma cinta de amarração e chumbar as vigas de madeira na cinta

Expectativa: que resultasse em bom acabamento superficial do topo da taipa.

As built: as paredes foram executadas com altura maior do que o projetado e cortadas com serra mármore e talhadeira e não houve a aplicação do solocimento plástico. As vigas frechais foram chumbadas nos topos da taipa com barra de aço roscada (com pontas afiadas) e resina epóxi, com desenho similar ao proposto.

Avaliação: em todas as paredes, o volume compactado excedente foi muito maior do que o necessário, resultando em dificuldade para a realização do corte. $\mathrm{O}$ acabamento dos topos apresentou defeitos (partes desagregadas, desniveladas, mal compactadas e algumas fissuras entre camadas). A interface entre a madeira e taipa não apresentou bom resultado, devido à irregularidade da taipa, resultando em frestas para a entrada de insetos e poeira. A superfície áspera do topo também interfere nas condições de limpeza e manutenção da edificação.

Modificação sugerida: moldar um lastro de concreto de $5 \mathrm{~cm}$, antes da desforma, para proteger, nivelar e dar acabamento aos topos. Outra opção é realizar o corte do excedente logo após a desforma, com a taipa ainda úmida.

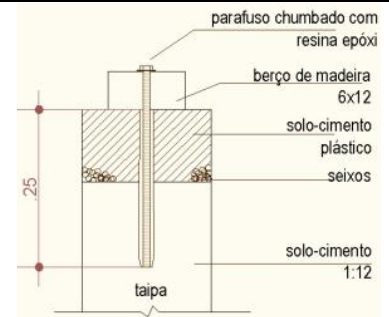

Proposta inicial

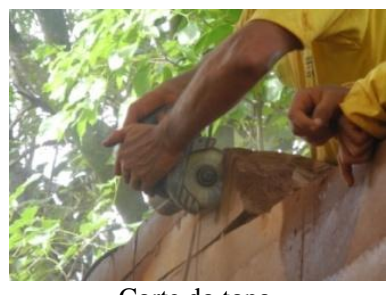

Corte do topo

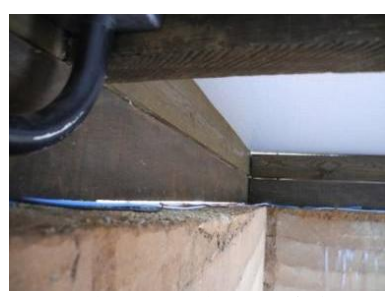

Acabamento da superfície

Fonte: CCS/UFMS e do autor

\section{Quadro 6 - Taipa-esquadrias}

Proposta: assentar o batente das portas com espuma de poliuretano

Expectativas: que na colocação dos batentes a espuma regularizasse a falta de prumo dos vãos, evitando patologias.

As built: as paredes de taipa foram desbastadas com serra mármore para recuperar o prumo, o que ocasionou fissuras e desagregações. Os batentes foram parafusados à taipa.

Avaliação: não apresentou problemas de estanqueidade por serem zonas protegidas de chuva (partes cobertas), nem salubridade e desconforto tátil. No entanto, o desbaste das paredes com serra mármore foi de difícil execução, além de ter gerado os problemas citados.
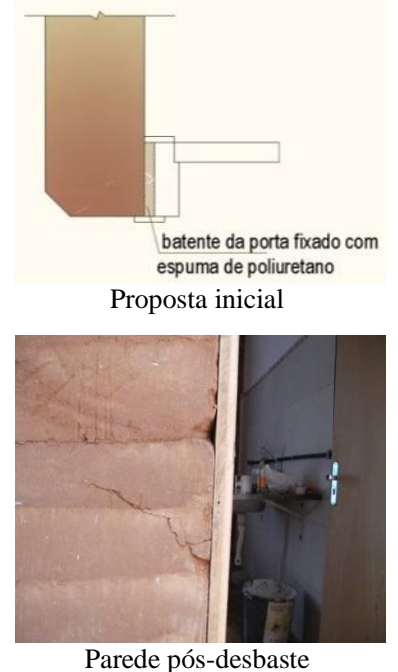

Fonte: do autor 


\section{Quadro 7 - Taipa-instalações}

Proposta: executar as instalações elétricas aparentes e a hidráulica embutida em paredes de alvenaria

Expectativa: não fazer cortes nas paredes para o embutimento, nem inserir dentro da forma durante a moldagem das paredes, para evitar danos às tubulações pela força de compactação.

As built: conforme projeto.

Avaliação: os eletrodutos aparentes, dependendo da posição na parede, causam um certo desconforto visual, e que pode interferir também nas condições de uso dos ambientes. Quanto à exequibilidade foi uma solução econômica e de fácil execução e não provocou problemas na taipa.

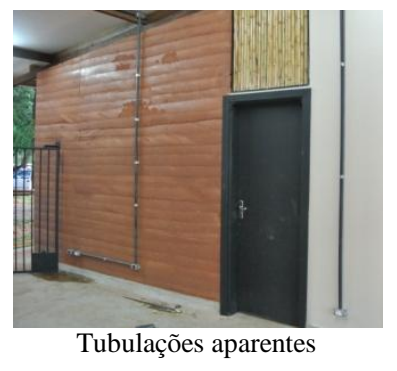

Fonte: do autor

\section{Quadro 8 - Taipa-revestimentos}

Proposta: proteger a superfície da taipa da umidade com o uso de consolidante. Nas paredes internas, revestir as paredes com maiores índices de patologias

Expectativas: que o uso da lixadeira suprisse a correção da maior parte de imperfeições da superfície (manchas, marcas de forma, protuberâncias).

As built: a aplicação de consolidante (silicone) nas paredes de taipa foi feita com um rolo e a tinta de terra na cor natural foi aplicada com esponja nas interfaces que necessitavam de correções. Na cozinha, na parede com várias patologias, foi aplicada uma pintura à base de massa PVA diluída na cor branca.

Avaliação: as microfibras de polipropileno, adicionadas à mistura de solocimento representaram resistência para o lixamento. O consolidante deu acabamento às paredes e fixou melhor as partículas, o que deverá contribuir para evitar o surgimento de novas patologias por esfarelamento ou abrasão. As tintas de terra, com aglomerante à base de PVA corrigiram as imperfeições estéticas e camuflaram as marcas de respingos e manchas de argamassa, porém destoaram da cor e textura originais da taipa. A aplicação da massa PVA na parede da cozinha corrigiu pequenas fissuras da parede 6.
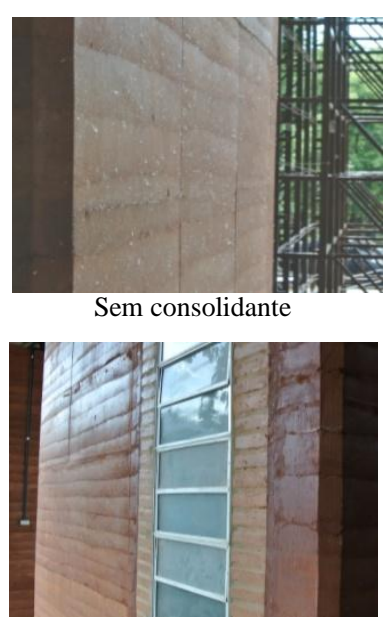

Com consolidante e tinta

Fonte: do autor

\section{CONSIDERAÇÕES FINAIS}

No geral, as interfaces e detalhes considerados satisfatórios são: chanfro das quinas, peça em "T" metálica entre parede e base de concreto, instalações, revestimentos e acabamentos. As interfaces que apresentaram mais problemas são as da taipa com alvenarias, provocadas pelos defeitos de prumo da taipa e falta de cuidado da mão de obra. As formas também demandam revisão, no projeto das contraformas, nas deformações e encaixes em "T". Cortes pós-secagem também não apresentaram bons resultados de acabamento.

Estudos como este, ganham significado num contexto de ausência de normas técnicas para a taipa, com normas de desempenho em vigor e necessidades de viabilização de alternativas tecnológicas mais sustentáveis. Embora dirigido a uma parte da edificação (paredes), procura detectar a influência das outras partes sobre o elemento estudado e a possível intervenção dos usuários quando em uso. As informações geradas sobre o desempenho da técnica construtiva poderão contribuir para a evolução da tecnologia de terra. Estudos futuros deverão ser realizados, apontando novos resultados relacionados ao desempenho dessas interfaces e também considerando os requisitos que não foram avaliados nesta pesquisa. 


\section{REFERÊNCIAS BIBLIOGRÁFICAS}

ASSOCIAÇÃO BRASILEIRA DE NORMAS TÉCNICAS (ABNT). NBR-15575: Edificações Habitacionais - Desempenho. Rio de Janeiro, 2013.

Câmara Brasileira da Indústria da Construção (CBIC). Desempenho de edificações habitacionais: guia orientativo para atendimento à norma ABNT NBR 15575/2013. Fortaleza: Gadiole Cipolla Comunicação, 2013, 300p.:il

CLAIR, E., COURT, J. (Coord) Rénover et construire en pisé. Parc Naturel Régional Livradois-Forez. 2011.

Centro de Pesquisas e Desenvolvimento (CEPED). Manual de construção com solo-cimento. 3ª edição. São Paulo: CEPED/ BNH/ URBIS/ CONDER/ PMC/OEA/CEBRACE/ ABCP, 1984. $147 \mathrm{p}$.

FONSECA, I. Arquitectura de Terra em Avis. 1 ${ }^{\text {a }}$. Edição. Lisboa, Portugal: Argumentum, 2007, $143 \mathrm{p}$.

GONZÁLES, F. D. Geometrias da Arquitetura de terra: A sustentabilidade Geométrica das construções em Terra Crua. Lisboa: Universidade Lusíada Editora, 2006, 203p.

HOFFMANN, M. V.; MINTO F. C. N ; HEISE A. F. apud NEVES, FARIA (Org). Técnicas de construção com terra. Bauru : FEB-UNESP / PROTERRA, 2011. 79 p. il. [Projeto de Investigação XIV.6. 2005. 31p. Programa Ibero-Americano de Ciência e Tecnologia para o Desenvolvimento-CYTED]

INTERNATIONAL ORGANIZATION FOR STANDARDIZATIOS (ISO). ISO 6241:1984. Performance standards in buildings: principles for their preparation and factors to be considered, ISO 6241. London, 1984.

JAGADISH, K. S. The progress of stabilized soil construction in India. In: Proceedings of National Seminar on Application of stabilized mud blocks in Housing and Building, Bangalore, India, November 1988, pp. 17-43.

JAQUIN, P. Historic Rammed Earth, 2008. Disponível em : http://historicrammedearth.co.uk/ rammed_earth.htm. Acesso em: 17 de maio de 2014.

SUZUKI D., KRAYENHOFF, M. Sirewall: stabilizer insulated rammed earth. Disponível em : http://www.sirewall.com/about/sirewall-system/. Acesso em: 12 mar. 2014.

VENKATARAMA REDDY, B. V., JAGADISH, K. S. Embodied energy of common and alternative building materials and Technologies. Energy and buildings 35. 2003. 129-137. May, 2001.

MANIATIDIS,V., WALKER, P. A Review of Rammed Earth Construction - Dti Partners in Innovation Project 'Developing Rammed Earth for UK Housing'. Natural Building Technology Group, Department of Architecture \& Civil Engineering, University of Bath, 2003.

MINKE, G. Manual de construcción para viviendas antisísmicas de tierra. 1a. edição, 2001. Universidad de Kassel, Alemanha.

WALKER, P., STANDARDS AUSTRALIA. The Australian Earth Building Handbook. Watford, BRE Bookshop.2005

\section{AGRADECIMENTOS}

À FUNDECT, CNPq, UFMS, Taipal Construções em Terra, Construgreen, Neomatex, Votorantim Cimentos, Sermix, Batlab, Ecomáquinas, Quartozolit, SF Formas, Mineração Xerez, Cerâmica Volpini. 